\title{
High pressure intensification of cassava resistant starch (RS3) yields
}

Article

Accepted Version

Lertwanawatana, P., Frazier, R. and Niranjan, K. (2015) High pressure intensification of cassava resistant starch (RS3) yields. Food Chemistry, 181. pp. 85-93. ISSN 0308-8146 doi: https://doi.org/10.1016/j.foodchem.2015.02.005 Available at https://centaur.reading.ac.uk/39412/

It is advisable to refer to the publisher's version if you intend to cite from the work. See Guidance on citing.

To link to this article DOI: http://dx.doi.org/10.1016/j.foodchem.2015.02.005

Publisher: Elsevier

All outputs in CentAUR are protected by Intellectual Property Rights law, including copyright law. Copyright and IPR is retained by the creators or other copyright holders. Terms and conditions for use of this material are defined in the End User Agreement.

\section{www.reading.ac.uk/centaur}

\section{CentAUR}

Central Archive at the University of Reading

Reading's research outputs online 


\section{High Pressure Intensification of Cassava Resistant Starch (RS3) Yields}

\author{
Proyphon Lertwanawatana*, Richard A. Frazier ${ }^{\mathrm{a}}$, and Keshavan Niranjan ${ }^{\mathrm{b}}$ \\ Department of Food and Nutritional Sciences, University of Reading, Whiteknights, PO Box 226, Reading, RG6 \\ 6AP, United Kingdom
}

\section{Abstract}

Cassava starch, typically, has resistant starch type 3 (RS3) content of $2.4 \%$. This paper shows that the RS3 yields can be substantially enhanced by debranching cassava starch using pullulanase followed by high pressure or cyclic high-pressure annealing. RS3 yield of $41.3 \%$ was obtained when annealing was carried out at $400 \mathrm{MPa} / 60^{\circ} \mathrm{C}$ for $15 \mathrm{~min}$, whereas it took nearly $8 \mathrm{~h}$ to obtain the same yield under conventional atmospheric annealing at $60^{\circ} \mathrm{C}$. The yield of RS3 could be further significantly increased by annealing under $400 \mathrm{MPa} / 60^{\circ} \mathrm{C}$ pressure for 15 min followed by resting at atmospheric pressure for $3 \mathrm{~h} 45 \mathrm{~min}$, and repeating this cycle for up to six times. Microstructural surface analysis of the product under a scanning electron microscope showed an increasingly rigid density of the crystalline structure formed, confirming higher RS3 content.

Keywords: Debranched cassava starch; High pressure annealing treatment; Type 3 resistant starch

*E-mail: p.lertwanawatana@student.reading.ac.uk, Rainyshine2@hotmail.com

a E-mail: r.a.frazier@reading.ac.uk, Tel: +44 (0) 118378 8709, Fax: + 44 (0) 1189310080

b E-mail: afsniran@reading.ac.uk, Tel: + 44 (0) 118378 8388,Fax: + 44 (0) 1189310080 


\section{Introduction}

Resistant starch (RS) is the non-digestible starch, which can resist the digestion by $\alpha$-amylase and act like dietary fibres - that helps to promote the growth of beneficial bacteria in the intestine (Englyst, Kingman, \& Cummings, 1992). Depending on its botanical origin and process employed to form it, RS can be divided into four categories: RS1 is physically inaccessible for reasons such as starch entrapment in a protein matrix or a plant cell wall (e.g. in seeds and unprocessed whole grain); RS2 is raw granular starch which cannot be absorbed by small intestine (e.g. those from potato and green banana); RS3 is retrograded starch, mainly retrograded amylose formed during cooking and cooling processes; and RS4 is chemically modified starch which is cross-linked by chemical agents and insusceptible to digest and absorb in the small intestine (Chung, Donner, \& Liu, 2011).

In general, many methods involving physical, chemical and enzymatic transformations have been employed to alter the properties of starch, which enhance health attributes and/or minimize defects in structure. Researchers have attempted to improve the RS yields by: 1) heat-moisture treatment and annealing (Brumovsky \& Thompson, 2001), 2) enzyme treatment (Vatanasuchart, Tungtrakul, Wongkrajang, \& Naivkul, 2010; H. Zhang \& Jin, 2011), 3) combined heat/enzyme treatment (Mutungi, Rost, Onyango, Jaros, \& Rohm, 2009) and 4) chemical treatment (Haynes et al., 2000). Since consumers are increasingly interested in natural and organic foods for health and environmental reasons, employing physical and/ or enzymatic treatment appears more attractive.

Although gelatinized starch retrogrades upon cooling and typically has a negative effect on the quality of starchy foods, low-temperature storage leads to the formation of retrograded starch or RS3 fraction. RS3 is of particular interest as a food ingredient because of its physical and nutritional functionality and processing stability (Thompson, 2000). Several factors influence 
the quality and quantity of RS3 in addition to storage conditions: amylose (a substantially linear glucose polymer) and amylopectin (a mainly branched glucose polymer) ratio, length of polymer chains or degree of polymerization (DP), retrogradation or recrystallization of amylose, water content, processing steps/conditions, and the presence of lipid and other components influencing gelatinization and/or the retrogradation process (Eerlingen \& Delcour, 1995). In addition, there are a number of studies have demonstrated that the higher the level of amylose, the greater the RS3 fraction formed (Brown, Mcnaught, \& Moloney, 1995). As a consequence, using a debranching enzyme like pullulanase to act on gelatinized starch has become one of the most important methods employed to directly cleave the branches of amylopectin and produce linear $\alpha$-glucan chains (Pongjanta, Utaipattanaceep, Naivikul, \& Piyachomkwan, 2009; Vatanasuchart et al., 2010; H. Zhang \& Jin, 2011).

Based on studies involving physically modified starches, research has indicated that the high hydrostatic pressure (HHP) plays an important role in inducing gelatinization of starches while still maintaining their granular integrity (Kasemwong, Ruktanonchai, Srinuanchai, Itthisoponkul, \& Sriroth, 2011; Oh, Pinder, Hemar, Anema, \& Wong, 2008). However, subsequent to HHP treatment, a rapid retrogradation has been observed (Kawai, Fukami, \& Yamamoto, 2007). Additionally, a combination of pressure and temperature can create more nuclei in starches (Hartel, 2001) and lead to a higher yield of recrystallized starch as a resistant starch product. This treatment was used for wheat starch to produce resistant starch following several steps such as annealing and storage, enzyme/acid hydrolysis and annealing-pressure cycle (Bauer, Wiehle, \& Knorr, 2005). It has been reported that a combination of treatments enhances the yields of RS in wheat starch more than by using individual processes such as HHP or thermal treatment.

Native cassava or tapioca starch (Maniho esculenta Crantz) is one of the food ingredients consisting of $17 \%$ amylose and 83\% amylopectin (Breuninger, Piyachomkwan, \& Sriroth, 2009). Given its high degree of branching, a higher formation of RS3 fraction may be expected by 
73

debranching (Mutungi, Onyango, Jaros, Henle, \& Rohm, 2009; Vatanasuchart et al., 2010). Furthermore, there are many methods available to improve the recrystallization of debranched cassava starch, such as by annealing, autoclaving-cooling cycle and/or heat-moisture treatment resulting in the rise of RS3 content (Mutungi, Rost, et al., 2009).

Despite its promising potential, very limited information exists within published scientific literature on the effects of high hydrostatic pressure (HHP) on retrograded resistant starch or the RS3 content of debranched starch, particularly from cassava or tapioca. This study explores the potential of forming RS3 in the structure resulting from the recrystallized debranched cassava starch, following the application of combined HHP and thermal annealing. This work also aims to evaluate the use of HHP within a solvent-free environment to maximise the production of RS3.

\section{Materials and methods}

\subsection{Materials}

Native cassava starch was supplied by Siam Modified Starch Co., Ltd (Thailand) in the form of white powder, containing less than $14 \%$ moisture and $0.2 \%$ ash content. Pullulanase solution (Sigma E2412, 1,824.68 U/ml), Trehalose (Fluka 90208), Maltotetraose (DP4 - Supelco 47877), Maltopentaose (DP5 - Supelco 47876), Maltohexaose (DP6 - Supelco 47873), Maltoheptaose (DP7 - Supelco 47872) were all obtained from Sigma-Aldrich Co., Ltd. (United Kingdom). Resistant starch assay kit (K-RSTAR) was purchased from Megazyme International Ireland Ltd. (Ireland). All other chemicals was used were of analytical grade.

\subsection{Process steps to produce resistant starch from cassava starch}


Native cassava starch (NS) was hydrolysed by pullulanase enzyme to cleave the $\alpha 1,6$ glycosidic bonds at the branched points of amylopectin molecules; the method employed was adapted from Mutungi, Rost, et al. (2009). A stock solution of pullulanase (Sigma E2412) was diluted in 20 $\mathrm{mM}$ sodium acetate-hydrochloric acid buffer ( $\mathrm{pH} 5.0)$ to $25 \mathrm{U} / \mathrm{ml}$ before use. The starch $(20 \mathrm{~g})$ was weighed into $250 \mathrm{ml}$ polycarbonate centrifuge bottle and suspended in $140 \mathrm{ml}$ of $20 \mathrm{mM}$ sodium acetate-hydrochloric acid buffer $(\mathrm{pH} 5.0)$. The starch suspension $(12.5 \% \mathrm{w} / \mathrm{w})$ was gelatinized by autoclaving at $121^{\circ} \mathrm{C}$ for 15 min and cooled to $50^{\circ} \mathrm{C}$. The starch gel was mixed with $20 \mathrm{ml}$ of $25 \mathrm{U} / \mathrm{ml}$ pullulanase solution. This mixture $(11 \% \mathrm{w} / \mathrm{w}$ starch) was incubated at $50^{\circ} \mathrm{C}$ in a shaking water bath (Grant OLS 200, Cambridge, UK) at 100 stroke/min in linear motion for $24 \mathrm{~h}$. The residue was recovered after inactivating the enzyme by washing thrice with chilled deionized water (temperature $<4{ }^{\circ} \mathrm{C}$ ) and centrifuging for $10 \mathrm{mins}$ at $3000 \mathrm{rpm}$ (Sorvall RC-5B Plus, Kendro, Newtown, USA). The use of chilled water for inactivating this enzyme has been employed earlier by Mutungi, Rost, et al. (2009). The pellet was freeze-dried (Martin Christ Gamma 2-16, Osterode am Harz, Germany), ground in a mortar, and sieved through a mesh size of $212 \mu \mathrm{m}$. This sample was termed DS.

\subsubsection{Incubation of debranched-autoclaved cassava starch}

The effect of incubation condition on the yields of RS3 from the debranched-autoclaved cassava starch (DAS) was determined. A $2 \times 5 \times 5$ factorial experiment covering starch solution concentration, temperature and time, was performed and carried out in triplicates. The DS (0.5 g) was weighed into $30 \mathrm{ml}$ glass vial and mixed with 4.5 and $2 \mathrm{ml}$ deionized water to form 10 and $20 \%(\mathrm{w} / \mathrm{w})$ concentrated solutions, respectively. The mixtures were autoclaved at $121^{\circ} \mathrm{C}$ for $15 \mathrm{~min}$ and cooled to $50^{\circ} \mathrm{C}$. These samples were allowed to stand for $15 \mathrm{~min}$ at ambient temperature before incubating at $4^{\circ} \mathrm{C}$ (in a fridge), $20,50,60$ and $90^{\circ} \mathrm{C}$ (in water baths) for 0.25 , 
2, 4, 8, and 24 h. The two sets of solutions (i.e. 10 and 20\%) were freeze-dried (VirTis Bench Top K Series, SP Industries, Warminster, PA, USA). These samples were referred to as: DAS10 (i.e. the one from 10\% DS) and DAS-20 (from the 20\% DS).

\subsubsection{Pressurizing of debranched-autoclaved cassava starch}

The effect of high hydrostatic pressure annealing on the development of RS3 content was investigated. The debranched starch (DS, $0.5 \mathrm{~g}$ ) was weighed into $30 \mathrm{ml}$ glass vial and mixed with $2 \mathrm{ml}$ deionized water and autoclaved at $121^{\circ} \mathrm{C}$ for $15 \mathrm{~min}$ to make the DAS-20. The resulting gel was transferred to a polyethylene pouch; vacuum packed (Mutivac A300, Wolfertschwenden, Germany), and pressurized in a high-pressure vessel (37mm diameter and 246 mm length) (Stansted Fluid Power type Food Lab 900, Stansted, U.K), where the temperature was controlled at $60^{\circ} \mathrm{C}$ by using a circulating thermostatic water bath (Grant B20632, Cambridge, UK). Two sets of experiments were undertaken in the high pressure rig:

In the first set of experiments, the pressure applied was constant and continuous for a given period of time. Packed samples of DAS-20 were pressurized at 200, 400 and $600 \mathrm{MPa}$ for 0.25 , $0.5,1,2,4,8$ and $24 \mathrm{~h}$ at $60^{\circ} \mathrm{C}$ to yield a $3 \times 7$ factorial experiments, each performed in triplicates. The samples were then unpacked and transferred to $15 \mathrm{ml}$ centrifuge tube before being freeze-dried. These samples were named HPT-DAS.

In the second set of experiments, the application of high pressure was intermittent or cyclic. The DAS-20 samples were subjected to pressure of $400 \mathrm{MPa}$ at $60^{\circ} \mathrm{C}$ for $15 \mathrm{~min}$ followed by atmospheric holding for $3 \mathrm{~h}$ and 45 min constituting one cycle; this cycle was repeated up to six times covering a total treatment period of $24 \mathrm{~h}$. Samples were drawn for analysis after each cycle, and RS3 contents were compared with a corresponding control sample, which was simply incubated at atmospheric pressure and $60^{\circ} \mathrm{C}$ for the same duration of time. This set of experiments therefore involved a $2 \times 6$ factorial performed in triplicates. The cyclic treated 
144 samples, named HPC-DAS, were then unpacked, transferred to $15 \mathrm{ml}$ centrifuge tube and

145 freeze-dried, individually.

\subsection{Measurement of chain length distribution of debranched starch}

148 High-performance anion exchange chromatography, equipped with pulsed amperometric 149 detector (HPAEC-PAD) and a CarboPac PA200 Dionex DX-600 (Dionex, Sunnyvale, CA, 150 USA) was undertaken to determine polymer chain length distribution of the debranched cassava starch. The sample prepared and condition employed were adapted from Dionex corporation (2004) and Mutungi, Rost, et al. (2009). Trehalose (10 mg) was suspended in $10 \mathrm{ml}$ of ultrapure water (UPW) and used as an internal standard. Molto-oligosaccharide standards (DP4 - DP7, 1 $\mathrm{mg} / \mathrm{ml}$ ) were prepared in $150 \mathrm{mM}$ aqueous sodium hydroxide solution and instantly diluted 50-

155 fold with UPW, containing $10 \mu \mathrm{l}$ of internal standard stock. The standards were performed to identify peak by comparing retention time of sample peaks with those of standards, and to predict peaks at the higher DP7 of samples according to the linear relationship between the retention time and the degree of polymerization. Debranched starch sample (DAS-20, $20 \mathrm{mg}$ ) was weighed into $2 \mathrm{ml}$ vials to which $400 \mu \mathrm{l}$ of $2 \mathrm{M}$ aqueous sodium hydroxide was added and mixed in a vortex mixer. This suspension was then diluted with $1600 \mu 1$ of ultrapure water and mixed in the same vortex mixer at $4^{\circ} \mathrm{C}$ and $450 \mathrm{rpm}$ for a further period of $24 \mathrm{~h}$. A $20 \mu \mathrm{l}$ aliquot $\mu 1$ internal standard stock. All samples were filtered though a $0.2 \mu \mathrm{m}$ filter and $25 \mu 1$ was auto-

164 injected at $0.5 \mathrm{ml} / \mathrm{min}$ flow rate into the column. The waveform and durations applied were as 165 follows: $E_{1}=0.1 \mathrm{~V}\left(t_{1} 0 \mathrm{~s}\right), E_{2}=0.1 \mathrm{~V}\left(t_{2} 0.20 \mathrm{~s}\right), E_{3}=0.1 \mathrm{~V}\left(t_{3} 0.40 \mathrm{~s}\right)$ (integration from 0.2 to $0.40 \mathrm{~s}), E_{4}=-2.0 \mathrm{~V}\left(t_{4} 0.41 \mathrm{~s}\right), E_{5}=-2.0 \mathrm{~V}\left(t_{5} 0.42 \mathrm{~s}\right), E_{6}=0.6 \mathrm{~V}\left(t_{6} 0.43 \mathrm{~s}\right), E_{7}=-0.1 \mathrm{~V}\left(t_{7} 0.44 \mathrm{~s}\right)$ and $E_{8}=-0.1 \mathrm{~V}\left(t_{8} 0.50 \mathrm{~s}\right)$. A gradient of $100 \mathrm{mM}$ sodium hydroxide solution (Eluent A) and 150 $168 \mathrm{mM}$ sodium hydroxide solution, containing $500 \mathrm{mM}$ sodium acetate (Eluent $\mathrm{B}$ ) was used for 
169

170

171

172

173

174

175

176

177

178

179

180

181

182

183

184

185

186

elution. Increasing concentration of eluent B from 5-40\% (0- $13 \mathrm{~min}), 40-85 \%$ (13- $50 \mathrm{~min})$ and decreasing to $5 \%(50-70 \mathrm{~min})$ were applied in linear gradients. Integrating area under individual peaks was determined by using Chromeleon ${ }^{\circledR}$ version 6.6 software (Dionex). This experiment was performed in triplicates.

\subsection{Determination of resistant starch}

The amount of resistant starch (RS) in all samples was investigated in triplicates using resistant starch assay kit (Megazyme, Bray, Ireland) - an enzymatic method recommended by the Association of Official Analytical Chemists (AOAC) Method 2002.02 (McCleary \& Monaghan, 2002). The main features of this procedure are: removal of non-resistant starch by hydrolysis and solubilisation using pancreatic $\alpha$-amylase and amyloglucosidase (AMG), washing the residue with ethanol, neutralization and enzymatic hydrolysis of RS to glucose using $2 \mathrm{M} \mathrm{KOH}$ acetate buffer and AMG, and measurement of RS by quantification of glucose with glucose oxidase/peroxidase reagent (GOPOD). The RS was calculated as mg glucose $\times 0.9$.

\subsection{Evaluation of microstructure}

The surface of the resistant starch samples were scanned using scanning electron microscope or SEM (S360, Leica Cambridge, UK). A small amount of dried sample was attached to electrically conductive double-sided adhesive carbon disc, which was pressed on a specimen stub. Gold was used to coat the sample using a sputter coater (S150B, BOC Edwards, Crawley, UK). The SEM operation conditions were: working pressure $<1.0 \mathrm{E}-4$ Torr, accelerating voltage $=20 \mathrm{kV}$ and working distance $=14 \mathrm{~mm}$ at the magnifications of $300 \times, 1000 \times$ and 
191

192

193

194

195

196

197

198

199

200

201

202

203

204

205

206

207

208

209

210

211

212

213

3000×. The image was recorded using IScan 2000 image software (ISS Group, Manchester, UK).

\subsection{Statistical analysis}

All RS percentages obtained were subjected to analysis of variance - ANOVA using PASW statistics 18.0 software (SPSS, IBM, Somer NY, USA). The results were expressed as mean values with standard deviation. The differences between the group mean values were established at $95 \%$ confidence interval $(P<0.05)$ using Duncan's new multiple range test (DMRT).

\section{Results and Discussion}

\subsection{Chain length distribution of debranched starch}

Native cassava starch was debranched using pullulanase and the chain length distribution of debranched starch was measured by high performance anion exchange chromatography equipped with pulsed amperometric detector (HPAEC-PAD). According to Hanashiro et al. (1996), branch chain types of amylopectin are classified by HPAEC to the group with periodicity of 12 as DP $6-12,13-24,25-36$ and DP $\geq 37$. These ranges of DP are referred to as A-chains, $B_{1}$-chains, $B_{2}$-chains and $B_{n(n \geq 3)}$-chains, respectively. In the present study, a polymer chain distribution between DP 4-45 was obtained and it is illustrated in Fig. 1. Most of the shorter chains were removed with cold water, showing the amount of chains of DP $\leq 5$ remaining, to be only $0.5 \pm 0.2 \%$. The proportion of A-chains (DP 6-12) was $23.0 \pm 0.6 \%$. The highest yield of $\mathrm{B}_{1}$-chains (DP 13-24) was found to be $50.6 \pm 1.1 \%$, whereas the $\mathrm{B}_{2}$-chains (DP 25-36) and $\mathrm{B}_{3}$ to $\mathrm{B}_{4}-$ chains $(\mathrm{DP} \geq 37)$ were lower at $22.0 \pm 0.3 \%$ and $3.9 \pm 0.6 \%$, respectively. These results indicate that the cassava amylopectin mainly comprises of $\mathrm{A}$ and $\mathrm{B}_{1}$-chains, which 
214 conforms to the literature results, even though it varies with the cultivars (Charoenkul, Uttapap,

215 Pathipanawat, \& Takeda, 2006; Mutungi, Rost, et al., 2009). The average chain length is DP

21620.5 , which is similar to the values observed in previous studies for debranched cassava starch

217 (Mutungi, Rost, et al., 2009; Tester, Karkalas, \& Qi, 2004). Schmiedl et al. (2000) also reported

218 that effective formation of RS3 can be produced from linear glucose chains of DP 10-35.

\subsection{Effect of debranching and autoclaving on the formation of RS3}

221 The RS contents of native starch (NS), debranched starch (DS), and debranched-autoclaved 222 starch (DAS) are presented in Table 1. After debranching, the amount of RS increases 223 drastically from $2.4 \pm 0.2 \%$ in NS to $17.4 \pm 0.5 \%$ in DS. These results are also consistent with 224 other studies that demonstrated debranching by using pullulanase enzyme in: 1) maize starch, 225 which increased the RS yield from 0.60 to $25.5 \%$ within 24 h (Marija, Milica, \& Ljubica, 2010); 226 and 2) corn starch, where RS yield increased from 0.67 to $19.02 \%$ within $12 \mathrm{~h}$ (Gao, Li, Jian, \& 227 Liang, 2011). This implies that the hydrolysis of $\alpha-1 \rightarrow 6$ linkages in amylopectin can produce 228 more linear structures similar to the amylose chains, and/or create free A-chains of amylopectin 229 in the form of double helix and crystallite segments. These debranched structures closely pack 230 into the crystal formation as retrograded starch (RS3) during retrogradation or the annealing 231 period (Vasanthan \& Bhatty, 1998).

232 Moreover, the results given in Table 1 confirm that the RS content of DS is higher than NS. It 233 may be mentioned here that there are conflicting reports in literature about the RS contents of 234 DS and NS. Mutungi, Rost et al. (2009) found that the RS content in DS (21.43g/100g) was 235 significantly lower compared to that in NS $(43.96 \mathrm{~g} / 100 \mathrm{~g})$, which was also observed by 236 Vatanasuchart et al. (2010). In contrast, Charles et al. (2005) noted that the initial RS yield in 237 five native cassava starches was only $6.8-14 \%$. These discrepancies may be due to the different 
238 botanical origin of cassava. It may also be noted that the RS fraction in NS is type 2 due to the

239 compact structure limiting the accessibility of the digestive enzyme in granular starch form,

240 whereas in DS, it is type 3 which results in retrograded polymer chains being formed in the

241 gelatinized starch (Mutungi, Rost, et al., 2009; Ozturk, Koksel, Kahraman, \& Ng, 2009).

242 After autoclaving of 10 and $20 \% \mathrm{w} / \mathrm{w}$ DS, the RS3 content of debranched-autoclaved starch

243 (DAS-10 and DAS-20) is significantly higher (22.0 \pm 0.5 and $28.3 \pm 1.0 \%$, respectively) than

244 that of DS $(17.4 \pm 0.2 \%)$. During the autoclaving experiment, the temperature was gradually

245 increased to $121^{\circ} \mathrm{C}$, maintained steady for $15 \mathrm{~min}$, and then cooled down to $50^{\circ} \mathrm{C}$ before taking

246 samples. The total time for this process was approximately $2 \mathrm{~h}$. Thus, the RS3 forms in two

247 steps that involve starch hydrolysis during autoclaving at a high temperature, followed by

248 recrystallization during cooling. It is important to note that the proportion of RS3 is strongly

249 enhanced when starch is debranched to increase the number of linear molecules prior to thermal

250 treatment (i.e. autoclaving). A similar response was also seen in the case of debranched-

251 autoclaved wheat starch (Berry, 1986) and banana starch (González-Soto, Agama-Acevedo,

252 Solorza-Feria, Rendón-Villalobos, \& Bello-Pérez, 2004).

253

\subsection{Effect of concentration, temperature and time on the formation of RS3}

255 Fig. 2 shows the proportion of RS3 in debranched-autoclaved cassava starch of two 256 concentrations (10 and $20 \% \mathrm{w} / \mathrm{w}$ of DS) at various temperatures $\left(4,20,50,60\right.$ and $\left.90^{\circ} \mathrm{C}\right)$, and 257 times $(0,0.25,2,4,8$ and $24 \mathrm{~h})$. The results suggest that there are significant interaction effects $258(P<0.05)$ between concentration, temperature and treatment time. The initial RS3 content of 259 debranched-autoclaved starch at the higher concentration DAS-20 (28.3 $\pm 1.0 \%$ RS $)$ is clearly 260 higher than DAS-10 $(22.0 \pm 0.5 \% \mathrm{RS})$. Thus, DAS-20 is more effective in recrystallization due 261 to re-association of a significant amount of short linear $\alpha$-glucan occurring with deionized water 
as the plasticizer. In contrast, DAS-10 has excessive water, leading to an obstruction of the intermolecular interaction between the hydrogen bonding of short chain fragments (Y. Zhang \&

264 Rempel, 2012).

265 After incubating, the RS3 contents in DAS-10 and DAS-20 are found to follow a similar trend. 266 The yield of RS gradually rises from 4 to $60^{\circ} \mathrm{C}$, and then drops at $90^{\circ} \mathrm{C}$. Theoretically, the 267 mechanism of recrystallization in amorphous polymers consists of nucleation, propagation, and 268 maturation - which represents crystal perfection by slow growth. The nucleation rate of linear 269 glucans largely increases as the temperature decreases to the glass transition temperature $\left(\mathrm{T}_{\mathrm{g}}\right)$ at 270 approximately $-5^{\circ} \mathrm{C}$, whereas the propagation rate increases as the temperature increases to the 271 melting temperature $\left(\mathrm{T}_{\mathrm{m}}\right)$ of about $150^{\circ} \mathrm{C}$ (Biliaderis, 2009; Ring et al., 1987). In other words, 272 the recrystallization correlates with the molecular mobility and crystal growth rate, and can 273 occur between $\mathrm{T}_{\mathrm{g}}$ and $\mathrm{T}_{\mathrm{m}}$ or in the glassy state (Marsh \& Blanshard, 1988). Consequently, the 274 treatment temperature at 4 and $20^{\circ} \mathrm{C}$ may be above and close to the $\mathrm{T}_{\mathrm{g}}$, which favours nuclei 275 formation, however, the crystals tend to develop slowly. Thus, the increased RS3 yield of DAS10 and DAS-20 at low temperature is not observed even after a prolonged incubation time to 24

$277 \mathrm{~h}$. The RS formation at $90^{\circ} \mathrm{C}$ also reveals a distinctively low value within $24 \mathrm{~h}$ at both 278 concentrations; this indicates that the temperature may be above $T_{m}$, which means the glucan 279 polymers are completely transferred into the liquid state. Therefore, there is no positional order 280 in the short chain molecules to result in the formation of RS. On the other hand, the formation of 281 increased RS3 in the case of DAS-10 and DAS-20 at 50 and $60^{\circ} \mathrm{C}$, further increased with 282 treatment time. The highest RS3 content of $29.6 \pm 0.5 \%$ in DAS-10 and $36.5 \pm 0.3 \%$ in DAS28320 is accomplished at $60^{\circ} \mathrm{C}$ after $4 \mathrm{~h}$. Clearly this temperature influences orientational mobility 284 and formation of double helices to promote crystal growth for retrograded starch (Jayakody \& 285 Hoover, 2008). In summary, based on the present study, the highest RS3 content is formed by 286 the autoclaving of $20 \%$ debranched starch solution at $60^{\circ} \mathrm{C}$ for $4 \mathrm{~h}$. 


\subsection{Effect of high-pressure processing and annealing on the formation of RS3}

289 Fig. 3 shows the effect of high-pressure treatments at $60^{\circ} \mathrm{C}$ on the yield of RS3 in DAS-20. It is 290 clear that the RS3 levels in DAS-20 can significantly improve by combining pressurizing at 400 $291 \mathrm{MPa}$ and annealing for various times (Fig. 3A); although at a treatment time of $24 \mathrm{~h}$, the 292 increase in RS3 is not significantly different $(P>0.05)$ between $400 \mathrm{MPa}$ HPT-DAS and the 293 control-annealed sample. During the first $15 \mathrm{~min}$, the RS3 formation in the combined treatment 294 at $400 \mathrm{MPa}$ surprisingly accelerated with a $25.7 \%$ increase (from $28.7 \pm 0.5 \%$ to $36.1 \pm 0.5 \%$ 295 RS), whereas the control-annealed sample only had a $9.7 \%$ increase of RS (from $28.7 \pm 0.5 \%$ to $29631.5 \pm 1.1 \% \mathrm{RS}$ ). These results clearly indicate that pressuring for short times provides a 297 significantly higher initial rate of recrystallization.

298 To obtain a higher yield of RS3, DAS-20 samples were subjected to cyclic high pressure 299 annealing treatment. As the results demonstrate, cyclic pressure annealing at prolonged 300 treatment times (Fig. 3B) can further enhance the RS3 formation. Although during the first $12 \mathrm{~h}$ 301 the increase in RS3 was not significantly different $(P>0.05)$ between HPC-DAS and HPT302 DAS at $400 \mathrm{MPa}$, after four to six cycles (16-24 h) the RS3 yield of HPC-DAS was greater than 303 that of either the $400 \mathrm{MPa}$ HPT-DAS and the control-annealed samples. A possible explanation 304 is that, the seed crystal formation occurs when the volume of the system decreases by increasing 305 pressure, forcing starch molecules closer together and creating more nuclei in the glassy state. 306 Although high-pressure application accelerates the nucleation rate, these nuclei are limited to 307 propagate. However, these seeds lead to the formation of large crystals when holding at 308 atmospheric pressure (lower pressure level). This scenario is similar to the high-pressure 309 crystallization of cumin aldehyde (essential oil) (Moritoki, Nishiguchi, \& Nishida, 1997) and 310 lysozyme (protein) (Moritoki, Nishiguchi, \& Nishida, 1995). Therefore, it implies that the 
311 propagation of crystalline DAS is restricted under high-pressure but cyclic pressure annealing improves the rate of propagation.

313 On the other hand, despite an increase in RS, HPT-DAS at 200 and $600 \mathrm{MPa}$ were not

314 significantly different in RS3 content between the groups, and their RS contents were lower than 315 the control sample even after pressurizing for $24 \mathrm{~h}$ (Fig. 3A). This behaviour is probably due to 316 limiting propagation of crystalline DAS under high-pressure conditions at $200 \mathrm{MPa}$, while the 317 low level of RS3 at $600 \mathrm{MPa}$ could be due to the crystalline melting of DAS. A number of 318 published papers report partial melting of the crystalline structure during compression at very 319 high pressure: for instance, at $650 \mathrm{MPa}$ in polylactides (Ahmed, Varshney, Zhang, \& 320 Ramaswamy, 2009); and at 740 - 1,500 MPa in several native starches, including normal corn, 321 waxy corn, wheat and potato starches (Liu, Selomulyo, \& Zhou, 2008).

322 Overall, the high hydrostatic pressure conditions for producing highest amount of RS3 are 323 suggested to be concurrently pressurizing DAS-20 at $400 \mathrm{MPa}$ and annealing at $60^{\circ} \mathrm{C}$ for $15 \mathrm{~min}$. 324 Clearly these conditions significantly reduce the process time, from $8 \mathrm{~h}$ (single incubating at $\left.60^{\circ} \mathrm{C}\right)$ to only 15 min with the same RS content generated $(36 \% \mathrm{RS})$ as in the case of the 326 conventional process. The highest RS yield was obtained after six cycles ( $24 \mathrm{~h}$ of total time) of 327 pressure alternating between $400 \mathrm{MPa}$ and atmosphere under the temperature of $60^{\circ} \mathrm{C}(41.9 \pm$ $3280.5 \%$ RS). Bauer et al. (2005) also noted increase in RS content from 2 to $12 \%$ in the case of 329 wheat starch when the pressure was increased to $500 \mathrm{MPa}$ for $15 \mathrm{~min}$ every $24 \mathrm{~h}$, over a period 330 of 10 days. Thus, it is important to note that high-pressure application on debranched starch 331 results in greater enhancement of RS compared to high-pressure treated native starch that still 332 maintains its granular form. 
335 The effects of: debranching and autoclaving on cassava starch (Fig. 4), concentration, 336 temperature and time (Fig. 5A), and high-pressure treatments on autoclaved samples (Fig. 5B)

337 were monitored using scanning electron microscopy (SEM). Fig. 4A shows the native starch

338 (NS) in a granular form. After debranching, the NS loses its granular structure, and then the 339 surface of DS appears more fluffy which indicates that the glucan polymers only reassociate 340 loosely (Fig. 4B). After autoclaving the DS, a densely packed surface region is evident in DAS 341 (Fig. 4C). In Fig. 5A, it is apparent that the DAS-20 incubation at $60^{\circ} \mathrm{C}$ for $4 \mathrm{~h}$ exhibits a 342 smoother area than DAS-10. When subjecting DAS-20 to high pressure annealing treatments, 343 Fig. 5B demonstrates that HPC-DAS after six cycles (24 h of process time) has a more densely 344 packed surface than HPT-DAS. It clearly shows less porosity and a smoother surface area, 345 which would yield greater resistance to enzyme digestion and increasing the RS content. The 346 overall microstructural observations show that RS3 content increases as the rigid dense crystalline structure increases.

\section{Conclusion}

350 The process employed plays an important role in accelerating retrogradation and the 351 transforming of native starch into RS3. In this study, the debranching step gave more linear 352 glucans and the autoclaving step aggregated these to increase crystallinity. High pressure 353 annealing subsequently accelerated RS formation within $15 \mathrm{~min}$, in contrast to atmospheric 354 annealing (single incubation) which required up to $8 \mathrm{~h}$ to result in the same yield of RS3. Thus, 355 process times can be drastically reduced using high pressure annealing. Yields of RS3 fraction 356 can be further increased following cyclic high pressure annealing of debranched-autoclaved 357 starch. The highest RS yield was obtained after applying six cycles ( $24 \mathrm{~h}$ of process time) of 358 pressure, each alternating between pressure application $\left(400 \mathrm{MPa} / 60^{\circ} \mathrm{C} / 15 \mathrm{mins}\right)$ to accelerate 
the nucleation rate of starch crystallization, and incubation (atmospheric pressure $/ 60^{\circ} \mathrm{C} / 3 \mathrm{~h} 45$ mins) for crystal propagation (41.9\% RS). These conditions gave the highest yield of RS3 from a $20 \% \mathrm{w} / \mathrm{w}$ solution of debranched-autoclaved starch. Thus, the high pressure annealing treatment is highly promising to increase RS yield. In addition, this method intensifies the formation of RS by physical modification (i.e. without using solvents), which is safer for food industry use.

\section{Acknowledgments}

The authors would like to thank the Thongpoon Wanglee foundation for financial support, and the Siam Modified Starch Co., Ltd, Thailand for providing the raw material (native cassava starch).

\section{Reference}

Ahmed, J., Varshney, S. K., Zhang, J.-X., \& Ramaswamy, H. S. (2009). Effect of high pressure treatment on thermal properties of polylactides. Journal of Food Engineering, 93(3), 308312. doi:10.1016/j.jfoodeng.2009.01.026

Bauer, B. A., Wiehle, T., \& Knorr, D. (2005). Impact of high hydrostatic pressure treatment on the resistant starch content of wheat starch. Starch - Stärke, 57(3-4), 124-133. doi:10.1002/star.200400334

Berry, C. S. (1986). Resistant-starch: Formation and measurement of starch that survives exhaustive digestion with amylolytic enzymes during the determination of dietary fibre. Journal of Cereal Science, 4(4), 301-314. doi:10.1016/S0733-5210(86)80034-0

Biliaderis, C. G. (2009). Chapter 8 - Structural transitions and related physical properties of starch. In J. N. BeMiller \& R. L. Whistler (Eds.), Starch: Chemistry and technology (3rd ed., pp. 293-372). San Diego: Academic Press. doi:10.1016/B978-0-12-746275-2.00008-2

Breuninger, W. F., Piyachomkwan, K., \& Sriroth, K. (2009). Chapter 12 - Tapioca/Cassava starch: Production and use. In J. N. BeMiller \& R. L. Whistler (Eds.), Starch: Chemistry and technology (3rd ed., pp. 541-568). San Diego: Academic Press. doi:10.1016/B978-012-746275-2.00012-4 
Brown, I. L., Mcnaught, K. J., \& Moloney, E. (1995). Hi-maize : New directions in starch technology and nutrition. Food Australia, 47(6), 272-275.

Brumovsky, J. O., \& Thompson, D. B. (2001). Production of boiling-stable granular resistant starch by partial acid hydrolysis and hydrothermal treatments of high-amylose maize starch. Cereal Chemistry, 78(6), 680-689. doi:10.1094/CCHEM.2001.78.6.680

Charles, A. L., Chang, Y. H., Ko, W. C., Sriroth, K., \& Huang, T. C. (2005). Influence of amylopectin structure and amylose content on the gelling properties of five cultivars of cassava starches. Journal of Agricultural and Food Chemistry, 53(7), 2717-25. doi:10.1021/jf048376+

Charoenkul, N., Uttapap, D., Pathipanawat, W., \& Takeda, Y. (2006). Simultaneous determination of amylose content \& unit chain distribution of amylopectins of cassava starches by fluorescent labeling/HPSEC. Carbohydrate Polymers, 65(1), 102-108. doi:10.1016/j.carbpol.2005.12.030

Chung, H.-J., Donner, E., \& Liu, Q. (2011). 4.43 - Resistant starches in foods. In M. MooYoung (Ed.), Comprehensive biotechnology (2nd ed., pp. 527-534). Burlington: Academic Press. doi:10.1016/B978-0-08-088504-9.00309-3

Dionex Corporation. (2004). Product manual for the CARBOPAC PA200 Guard Column (3 x $50 \mathrm{~mm}, \mathrm{P} / \mathrm{N}$ 062895) CARBOPAC PA200 Analytical Column ( 3 x $250 \mathrm{~mm}, \mathrm{P} / \mathrm{N} 062896)$. Retrieved from http://www.dionex.com/en-us/webdocs/38510-3199201_CP_PA200_V21.pdf

Eerlingen, R. C., \& Delcour, J. A. (1995). Formation, analysis, structure and properties of type III enzyme resistant starch. Journal of Cereal Science, 22(2), 129-138. doi:10.1016/07335210(95)90042-X

Englyst, H. N., Kingman, S. M., \& Cummings, J. H. (1992). Classification and measurement of nutritionally important starch fractions. European Journal of Clinical Nutrition, $46 \mathrm{Suppl}$ 2, S33-S50.

Gao, Q., Li, S., Jian, H., \& Liang, S. (2011). Preparation and properties of resistant starch from corn starch with enzymes. Journal of Biotechnology, 10(7), 1186-1193. doi:10.5897/AJB10.1381

González-Soto, R. A., Agama-Acevedo, E., Solorza-Feria, J., Rendón-Villalobos, R., \& BelloPérez, L. A. (2004). Resistant starch made from banana starch by autoclaving and debranching. Starch - Stärke, 56(10), 495-499. doi:10.1002/star.200400283

Hanashiro, I., Abe, J., \& Hizukuri, S. (1996). A periodic distribution of the chain length of amylopectin as revealed by high-performance anion-exchange chromatography. Carbohydrate Research, 283(0), 151-159. doi:10.1016/0008-6215(95)00408-4

Hartel, R. W. (2001). Crystallization in foods (p. 325). Gaithersburg, Md.: Aspen Publishers, Inc. 
Haynes, L., Gimmler, N., Locke, J. P., Kweon, M.-R., Slade, L., \& Levine, H. (2000). Process for making enzyme-resistant starch for reduced-calorie flour replacer. US Patent 6013299, January 11, 2000.

Jayakody, L., \& Hoover, R. (2008). Effect of annealing on the molecular structure and physicochemical properties of starches from different botanical origins - A review. Carbohydrate Polymers, 74(3), 691-703. doi:10.1016/j.carbpol.2008.04.032

Kasemwong, K., Ruktanonchai, U. R., Srinuanchai, W., Itthisoponkul, T., \& Sriroth, K. (2011). Effect of high-pressure microfluidization on the structure of cassava starch granule. Starch - Stärke, 63(3), 160-170. doi:10.1002/star.201000123

Kawai, K., Fukami, K., \& Yamamoto, K. (2007). Effects of treatment pressure, holding time, and starch content on gelatinization and retrogradation properties of potato starch-water mixtures treated with high hydrostatic pressure. Carbohydrate Polymers, 69(3), 590-596. doi:10.1016/j.carbpol.2007.01.015

Liu, Y., Selomulyo, V. O., \& Zhou, W. (2008). Effect of high pressure on some physicochemical properties of several native starches. Journal of Food Engineering, 88(1), 126-136. doi:10.1016/j.jfoodeng.2008.02.001

Marija, S. M., Milica, M. R., \& Ljubica, P. D. (2010). Effects of autoclaving and pullulanase debranching on the resistant starch yield of normal maize starch. Journal of the Serbian Chemical Society, 75(4), 449-458. doi:10.2998/JSC090904027M

Marsh, R. D. L., \& Blanshard, J. M. V. (1988). The application of polymer crystal growth theory to the kinetics of formation of the B-amylose polymorph in a $50 \%$ wheat-starch gel. Carbohydrate Polymers, 9(4), 301-317. doi:10.1016/0144-8617(88)90048-3

McCleary, B. V, \& Monaghan, D. A. (2002). Measurement of resistant starch. Journal of AOAC International, 85(3), 665-675.

Moritoki, M., Nishiguchi, N., \& Nishida, S. (1995). Crystallization of lysozyme at high pressures. Journal of Crystal Growth, 151(1-2), 173-179. doi:10.1016/00220248(95)00046-1

Moritoki, M., Nishiguchi, N., \& Nishida, S. (1997). Chapter 13 - Features of the high-pressure crystallization process in industrial use. In G. D. Bottsaris \& K. Toyokura (Eds.), Separation and Purification by Crystallization Vol. 667 (pp. 136-149). American Chemical Society. doi:10.1021/bk-1997-0667.ch013

Mutungi, C., Onyango, C., Jaros, D., Henle, T., \& Rohm, H. (2009). Determination of optimum conditions for enzymatic debranching of cassava starch and synthesis of resistant starch type III using central composite rotatable design. Starch - Stärke, 61(7), 367-376. doi:10.1002/star.200800119

Mutungi, C., Rost, F., Onyango, C., Jaros, D., \& Rohm, H. (2009). Crystallinity, thermal and morphological characteristics of resistant starch type III produced by hydrothermal treatment of debranched cassava starch. Starch - Stärke, 61(11), 634-645. doi:10.1002/star.200900167 
Oh, H. E., Pinder, D. N., Hemar, Y., Anema, S. G., \& Wong, M. (2008). Effect of high-pressure treatment on various starch-in-water suspensions. Food Hydrocolloids, 22(1), 150-155. doi:10.1016/j.foodhyd.2007.01.028

Ozturk, S., Koksel, H., Kahraman, K., \& Ng, P. (2009). Effect of debranching and heat treatments on formation and functional properties of resistant starch from high-amylose corn starches. European Food Research and Technology, 229(1), 115-125. doi:10.1007/s00217-009-1032-1

Pongjanta, J., Utaipattanaceep, A., Naivikul, O., \& Piyachomkwan, K. (2009). Debranching enzyme concentration effected on physicochemical properties and $\alpha$-amylase hydrolysis rate of resistant starch type III from amylose rice starch. Carbohydrate Polymers, 78(1), 59. doi:10.1016/j.carbpol.2009.03.037

Ring, S. G., Colonna, P., I'Anson, K. J., Kalichevsky, M. T., Miles, M. J., Morris, V. J., \& Orford, P. D. (1987). The gelation and crystallisation of amylopectin. Carbohydrate Research, 162(2), 277-293. doi:10.1016/0008-6215(87)80223-9

Schmiedl, D., Bauerlein, M., Bengs, H., \& Jacobasch, G. (2000). Production of heat-stable, butyrogenic resistant starch. Carbohydrate Polymers., 43(2), 183-193. doi:10.1016/S01448617(00)00147-8

Tester, R. F., Karkalas, J., \& Qi, X. (2004). Starch-composition, fine structure and architecture. Journal of Cereal Science, 39(2), 151-165. doi:10.1016/j.jcs.2003.12.001

Thompson, D. B. (2000). Strategies for the manufacture of resistant starch. Trends in Food Science \& Technology, 11(7), 245-253. doi:10.1016/S0924-2244(01)00005-X

Vasanthan, T., \& Bhatty, R. S. (1998). Enhancement of resistant starch (RS3) in amylomaize, barley, field pea and lentil starches. Starch - Stärke, 50(7), 286-291. doi:10.1002/(SICI)1521-379X(199807)50:7<286::AID-STAR286>3.0.CO;2-O

Vatanasuchart, N., Tungtrakul, P., Wongkrajang, K., \& Naivkul, O. (2010). Properties of pullulanase debranched cassava starch and type-III resistant starch. Kasetsart J. (Nat. Sci.), 44, 131-141. Retrieved from http://kasetsartjournal.ku.ac.th/kuj_files/2010/A1001141120475468.pdf

Zhang, H., \& Jin, Z. (2011). Preparation of resistant starch by hydrolysis of maize starch with pullulanase. Carbohydrate Polymers, 83(2), 865-867. doi:10.1016/j.carbpol.2010.08.066

Zhang, Y., \& Rempel, C. (2012). Retrogradation and antiplasticization of thermoplastic starch. In A. Z. El-Sonbati (Ed.), Thermoplastic Elastomers (pp. 117-134). InTech. Retrieved from http://www.intechopen.com/books/thermoplastic-elastomers/retrogradation-andantiplasticization-of-thermoplastic-starch 
503

504

505

506

507

508

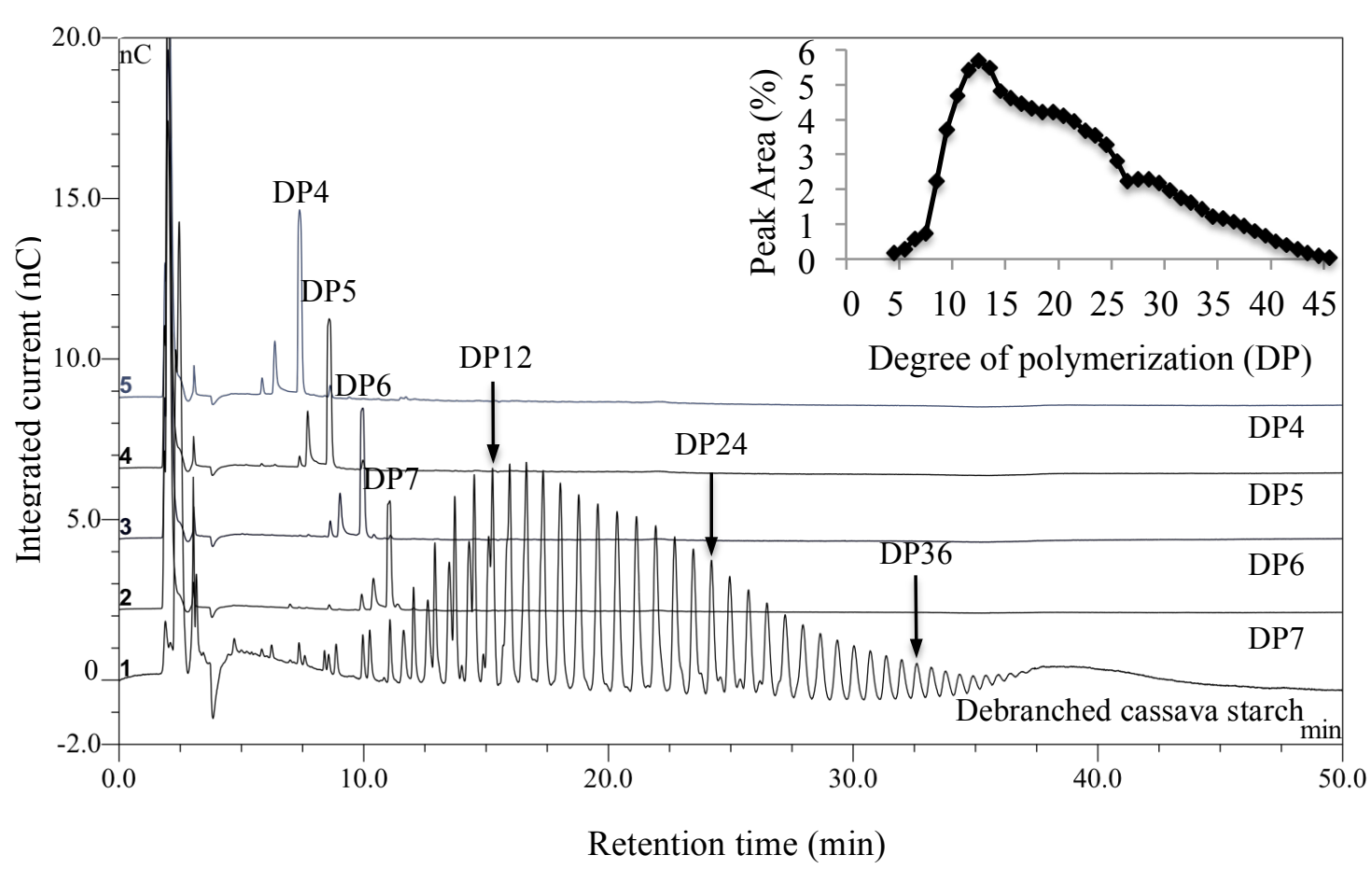

509

Retention time (min)

510

511 Fig. 1 Polymer chain length distribution of debranched amylopectin of cassava starch (DS)

512 using high performance anion exchange chromatography with pulsed amperometric detector

513 (HPAEC-PAD). The DP4-45 is shown in the chromatogram. DP4-7 peak labels indicate the DP

514 from molto-oligosaccharide standards. The inset shows the relative peak area for the individual

515 DP from the mean of three independent measurements.

516

517

518

519

520 
523

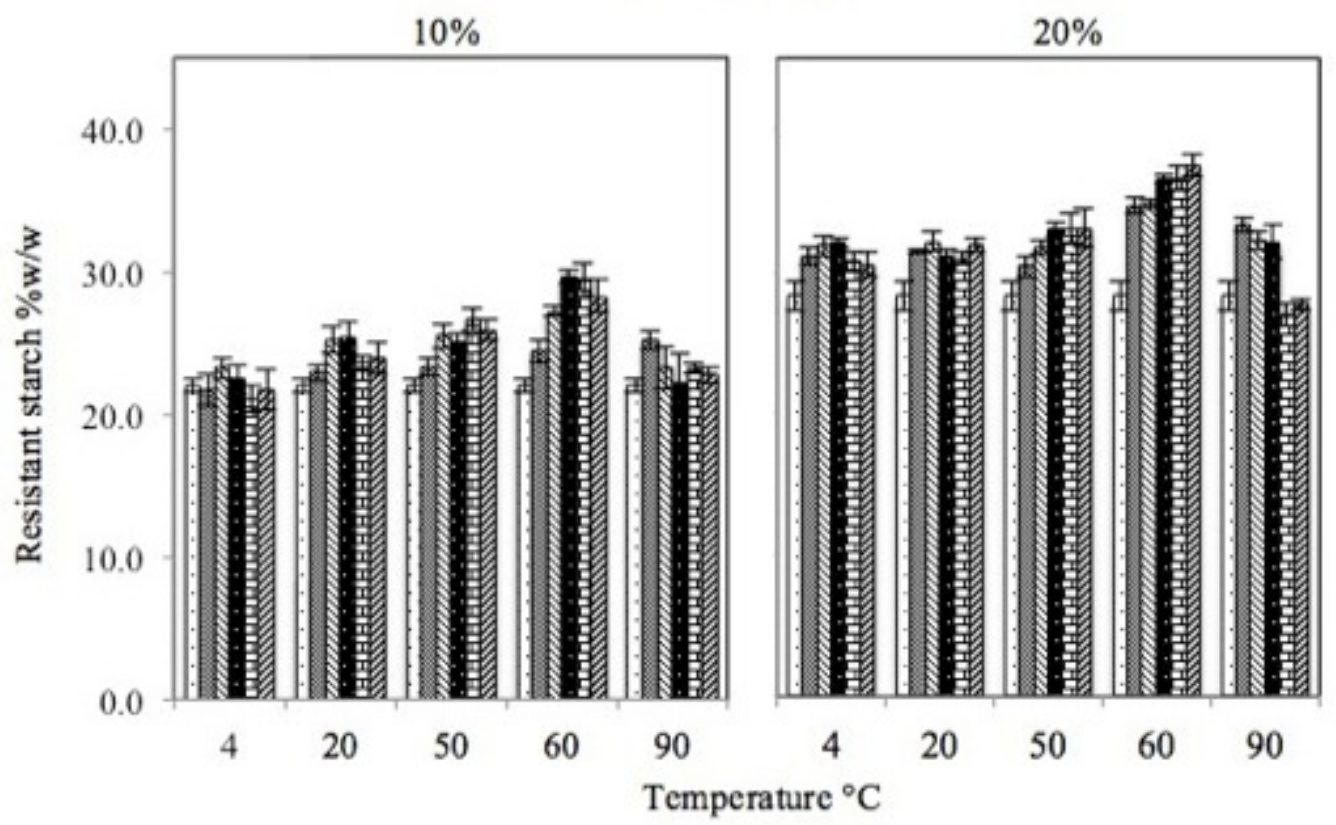

529

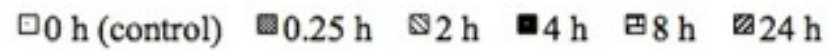

530

531 Fig. 2 Effect of concentration (10 and 20\%w/w of debranched starch), temperature (4, 20, 50, 60

532 and $\left.90^{\circ} \mathrm{C}\right)$ and time $(0,0.25,2,4,8$ and $24 \mathrm{~h})$ on yield of RS3 (\%w/w) of debranched533 autoclaved cassava starch (DAS).

534

535

536

537

538

539 


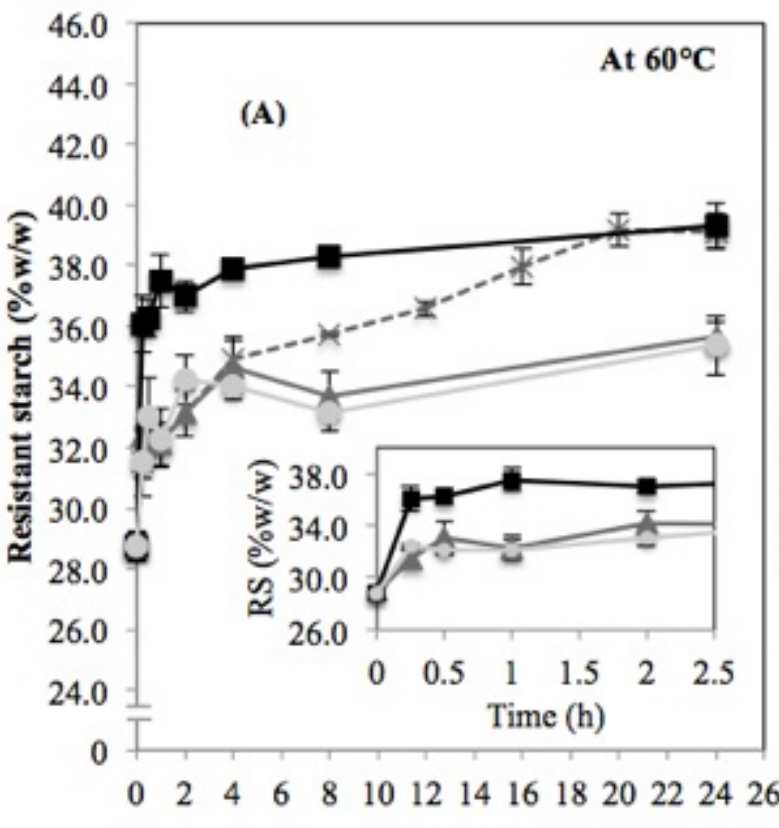

Time (h)

--)-- Annealing at atmospheric pressure

548

549

550

551

552

553

554

555

556

557

558 DAS, at any treatment time.

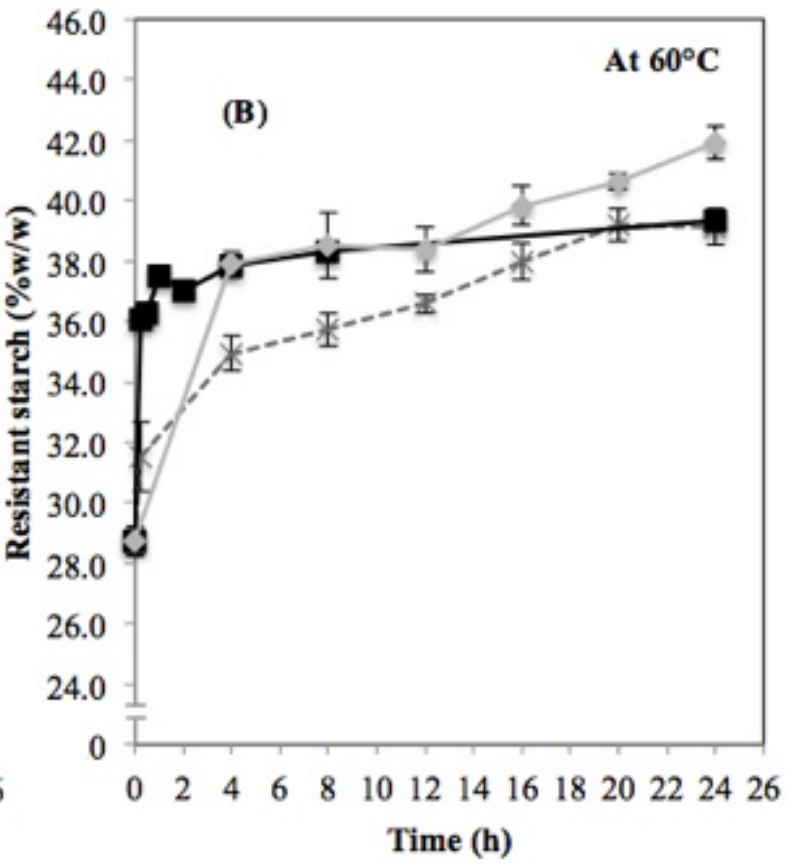

--\-- Annealing at atmospheric pressure $400 \mathrm{MPa}$, HPT-DAS

\section{$\longrightarrow-400 \mathrm{MPa}$ Pressure-annealing cycle, HPC-DAS}

Fig. 3 Effect of high-pressure incubation on yield of RS3 from debranched-autoclaved starch (DAS-20, 20\% w/w of debranched starch) (A) high pressure $(200,400$ and $600 \mathrm{MPa})$ at $60^{\circ} \mathrm{C}$ for different times $(0.25,0.5,1,2,4,8$ and $24 \mathrm{~h})$ : HPT-DAS. The inset to A shows increasing RS3 content on an expanded scale. (B) high pressure incubation at $400 \mathrm{MPa}$ and $60^{\circ} \mathrm{C}$ for 15 min followed by atmospheric holding at the same temperature for $3 \mathrm{~h} 45 \mathrm{~min}$, repeating this cycle for up to six times: HPC-DAS. Figure B also shows RS content comparison among control treatment (atmospheric annealing at $60^{\circ} \mathrm{C}$ ), $400 \mathrm{MPa}$ HPT-DAS and $400 \mathrm{MPa} \mathrm{HPC}-$ 
561

(A)
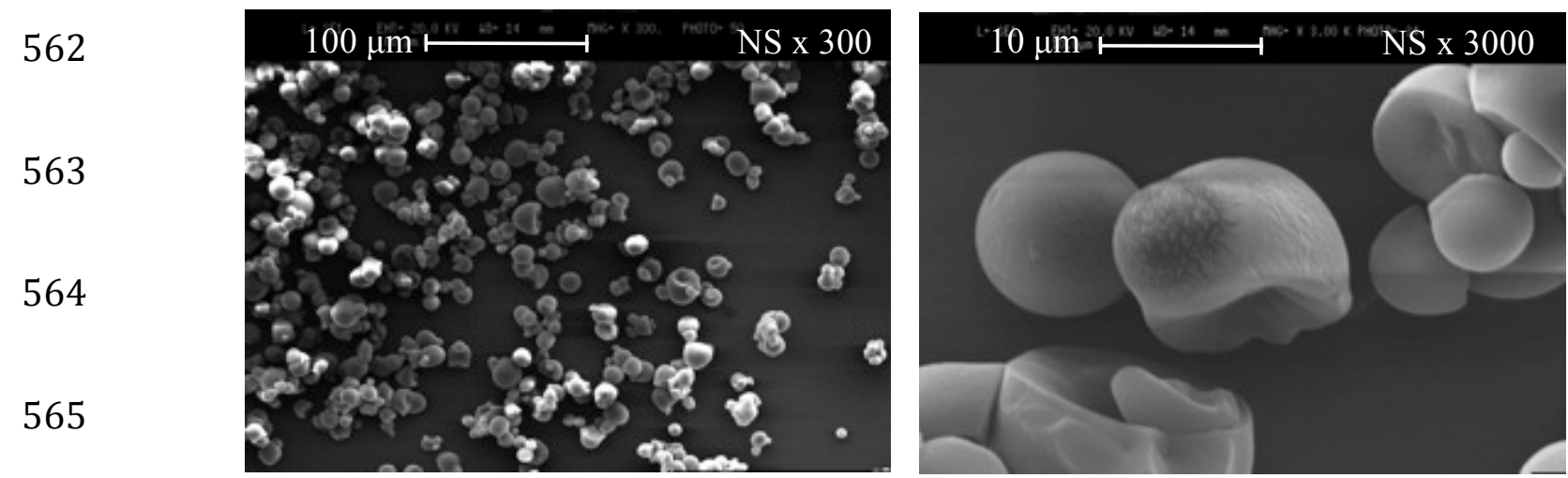

566

(B)

567

568

569
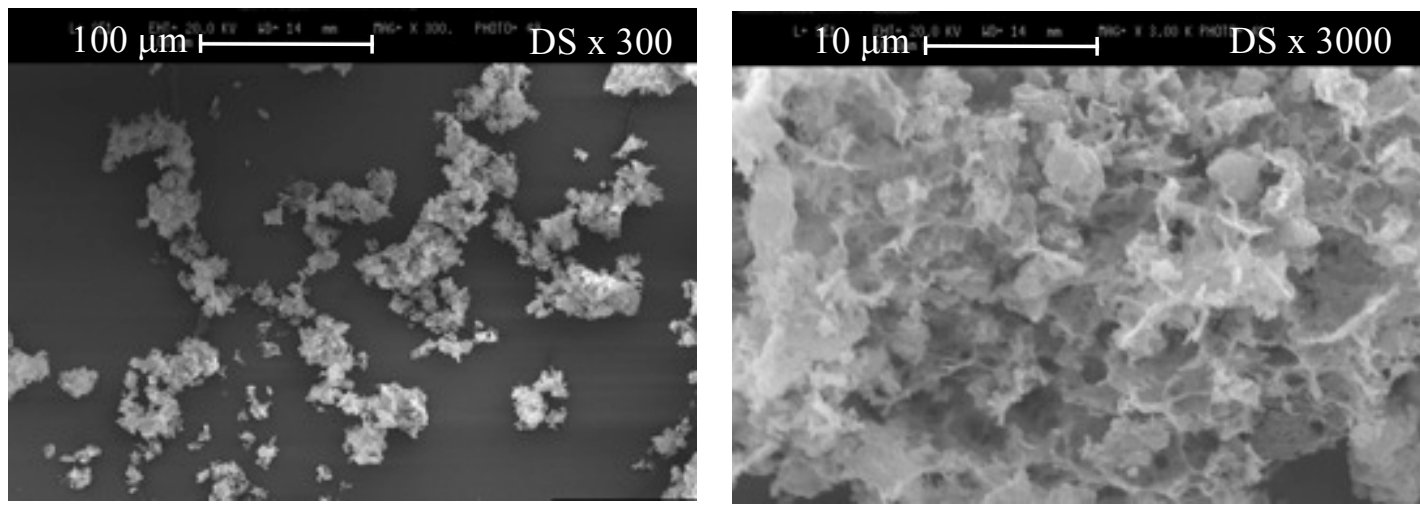

570

(C)

571
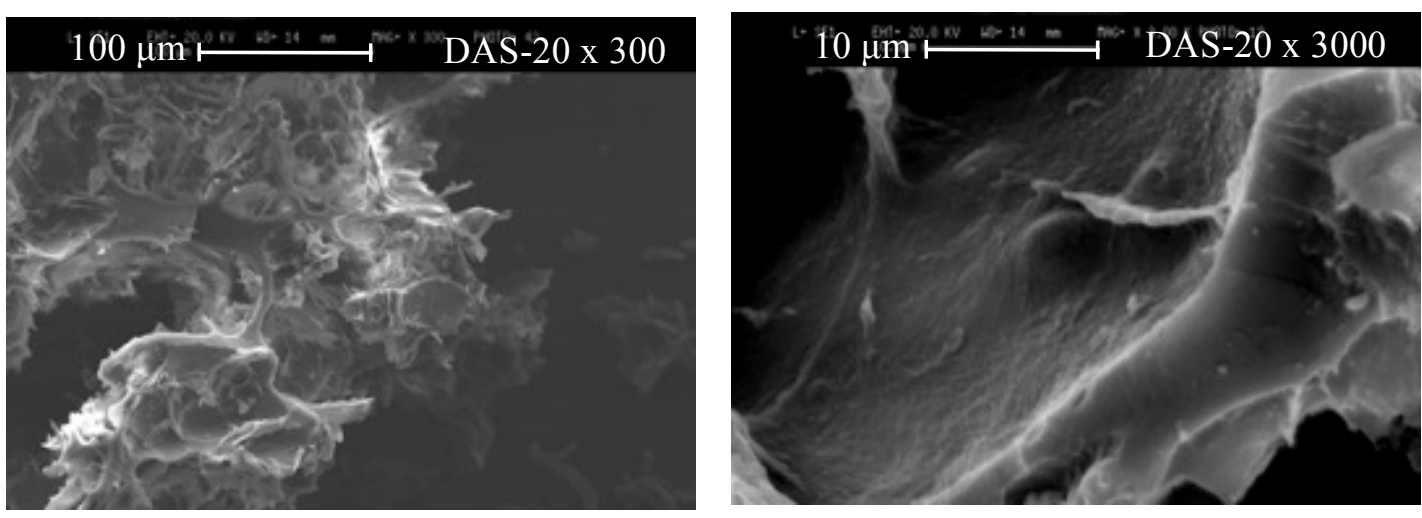

575 Fig. 4 Scanning electron micrographs at magnification of $300 \times$ and $3000 \times$ of (A) native

576 cassava starch: NS), (B) debranched starch: DS, and (C) debranched-autoclaved starch at

$57720 \% \mathrm{w} / \mathrm{w}$ of DS: DAS-20 
580

581

582

583

584

A (A2)

585

586

587

588

589

590

591

592

593

B

594

595

596

597

(A1)

(B1)

(B2)
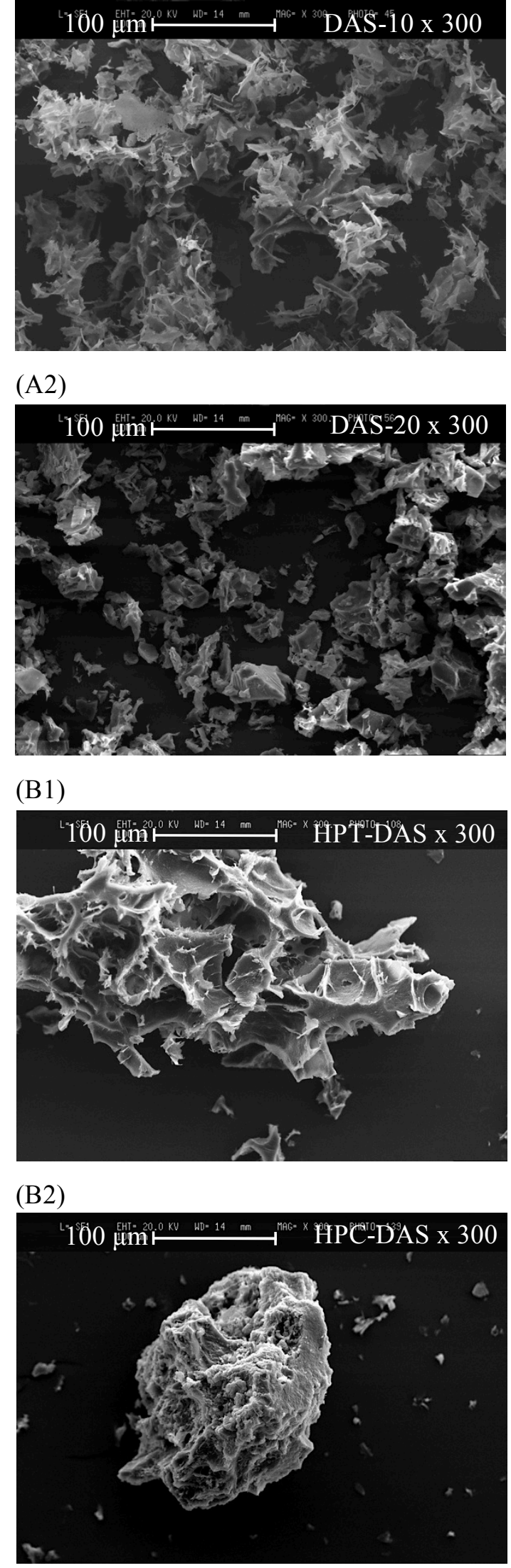
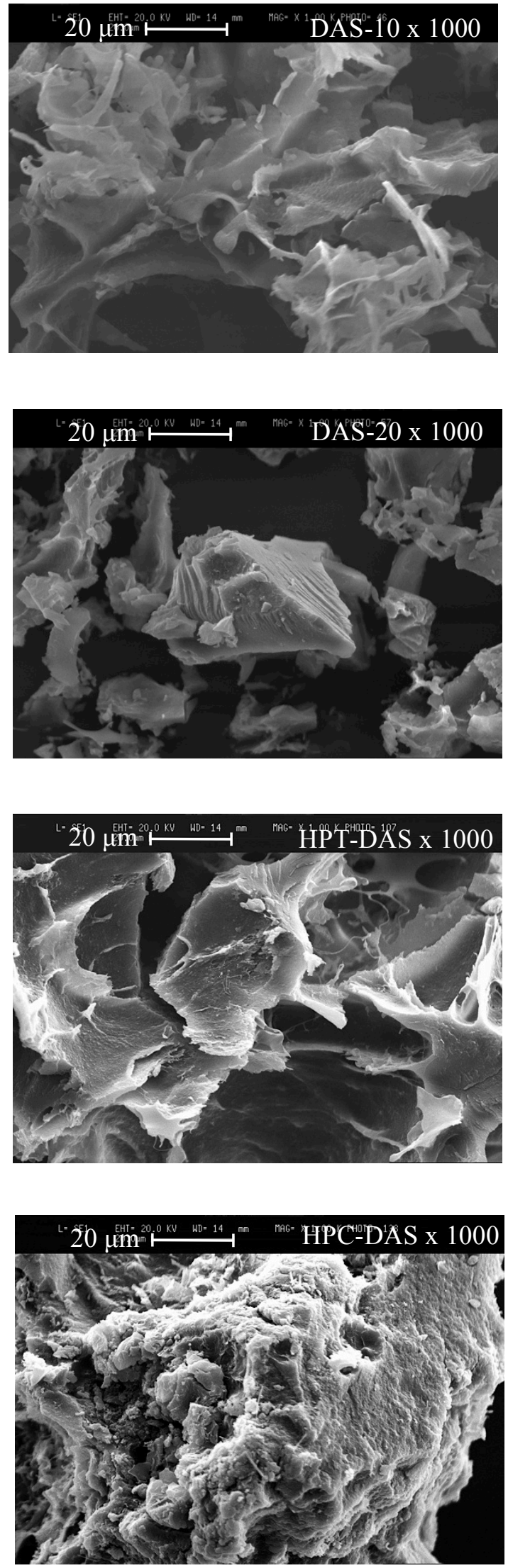
598 Fig. 5 (A) Scanning electron micrographs at magnification of $300 \times$ and $1000 \times$ after incubation 599 at $60^{\circ} \mathrm{C}$ for $4 \mathrm{~h}$ of (A1) debranched-autoclaved starch at $10 \% \mathrm{w} / \mathrm{w}$ of DS: DAS-10, and (A2) 600 debranched-autoclaved starch at 20\%w/w of DS: DAS-20. (B) Scanning electron micrographs at 601 magnification of $300 \times$ and $1000 \times$ of debranched-autoclaved starch at $20 \% \mathrm{w} / \mathrm{w}$ of debranched 602 starch after applying high pressure (B1) high pressure annealing treatment at $400 \mathrm{MPa}$ and $60^{\circ} \mathrm{C}$ 603 at a treatment time of $24 \mathrm{~h}$ : HPT-DAS, and (B2) cyclic high pressure annealing at $60^{\circ} \mathrm{C}$ after six 604 cycles with pressure swinging between $400 \mathrm{MPa}$ for $15 \mathrm{~min}$ and atmosphere for $3 \mathrm{~h} 45 \mathrm{~min}$ 605 over 24 h: HPC-DAS.

606

607

608

609

610

611

612

613

614

615

616

617

618

619

620

621 
622 Table 1: Effect of debranching and autoclaving on RS3 content of cassava starch

\begin{tabular}{|c|c|c|c|}
\hline Samples & $\begin{array}{c}\text { Resistant starch } \\
(\%)\end{array}$ & Starch sources & References \\
\hline NS & $2.4 \pm 0.2^{\mathrm{a}}$ & Siam Modified Starch Co. Ltd, & \\
\hline DS & $17.4 \pm 0.5^{b}$ & Thailand & \\
\hline DAS-10 & $22.0 \pm 0.5^{\mathrm{c}}$ & & \\
\hline DAS-20 & $28.3 \pm 1.0^{\mathrm{d}}$ & & \\
\hline NS & 43.9 & Kenya Industrial Research and & Mutungi, Rost, et al., \\
\hline DS & $21.4 \pm 2.7$ & Development Institute, Kenya & 2009 \\
\hline NS & $58.2 \pm 1.3$ & Taiwa Public Co., Ltd, & Vasanthan \& Bhatty, \\
\hline DS & $13.0 \pm 1.3$ & Thailand & 1998 \\
\hline \multirow[t]{3}{*}{ NS } & $6.8-14.0$ & 5 cassava genotypes (Rayong2, & Charles, Chang, Ko, \\
\hline & & Rayong5, KU50, Hanatee and & Sriroth, \& Huang, \\
\hline & & YOO2), Thailand & 2005 \\
\hline
\end{tabular}

624 Native starch; DS: Debranched starch; DAS-10: Debranched-autoclaved starch at 10\%DS; and DAS-20:

625 Debranched-autoclaved starch at $20 \%$ DS 